\title{
EFFECT OF NANOFLUIDS ON PERFORMANCE OF SOLAR APPLIANCES: A Review
}

\author{
Pradeep Kumar Sharma ${ }^{1}$, Manvijay Singh ${ }^{2}$ \\ ${ }^{1}$ Department of Mechanical Engineering, Dr. K.N. Modi University, Newai, Rajasthan \\ ${ }^{2}$ Department of Mechanical Engineering, Laxmi Devi Institute Of Engg. \& Technology, \\ Alwar, Rajasthan \\ Corresponding Author:vs3534@gmail.com
}

\begin{abstract}
:
The sun is a natural source of renewable energy. The use of solar energy may be especially important within global warming and the reduction of carbon dioxide emissions. solar energy is tested using solar thermal energy, photovoltaic energy development, and so on. Solar heat is the most common use around it. For solar-powered solar collectors, plates or tubes are coated with a layer of selective immersion fabric used to soak up solar energy, after which the energy is filled with excitement with the help of an active liquid within the heat form. This type of collector presents a number of shortcomings, including rules regarding incident congestion and relatively high heat loss. Lack of fossil fuels and environmental considerations have encouraged researchers to use energy sources that include solar energy. Therefore, it is important to maximize the efficiency and replicate solar thermal systems. Continuously, a few of the aforementioned nanofluid packages for thermal energy storage, solar cells, and sun exposure are being updated. Distribution defines the values of nanoparticles in a normal fluid base has a significant impact on the visible homes and the thermo-body of the fluid base. Enhancement of solar irradiance assimilation results in better heat transfer fines followed by more efficient heat transfer. Nanofluid suspension of nanoparticles in basic liquid, a new therapeutic goal of nanotechnology has been developed. Nanofluids have unique functions of a single type from a common stable liquid mixture in which $\mathrm{mm}$ or $\mu \mathrm{m}$ particles of metal and non-metallic particles are dispersed. due to its amazing properties, nanofluids are widely used to improve heat transfer. The purpose of this experimental manuscript is to examine nanofluids in solar panels. To overcome those problems, a direct sun suction collector has been used to exploit the heat of the sun.
\end{abstract}

Key words: Nanofluids, Solar energy, Solar collector, Sun etc.

\section{Introduction}

Nanofluids are novels that disperse liquids designed to disperse nanometer-based substances (Nanoparticles, nanofibers, nanotubes, nanowires, nanorods, nanosheet, or droplets) into basic liquids. In other words, nanofluids are nothing but a nanoscale colloidal suspension containing purified nanomaterials. There are two phase systems where one is associated with a solid phase and the other is related to a liquid phase. Nanofluids have been developed to obtain advanced thermo materials such as thermal flow, thermal variability, viscosity, and 
variable heat transfer coefficients compared to those of a basic liquid such as oil or water. It has been established with great applications to come in many fields.

The concept of nanofluid development is to use them as thermo fluids in temperature change to improve the heat transfer coefficient thereby reducing the size of the heat transfer material. Important parameters influencing the thermal transfer properties of nanofluids are its features which include thermal flexibility, viscosity, special heat and density. The thermal properties of nanofluids also depend on the effective temperature of the nanofluids. Therefore, accurate measurement of temperature-dependent properties of nanofluids is important. Ordinary liquids such as water, ethylene glycol, and heat exchangers play an important role in many production processes such as energy production, heating or cooling processes, chemical processes, and microelectronics. However, these fluids have a stumpy thermal conductivity and therefore cannot achieve high levels of heat transfer in thermal engineering equipment. The path to the ascending direction above this can enter the use of solid particles that are limited to conventional liquids to improve their thermal flexibility. The formation of nanosized particles $(1-100 \mathrm{~nm})$ in a common basic liquid is called nanofluid. Choi invented the nanofluids. Nanofluids, compared with suspensions with particles of millimeter-ormicrometer size, show better stability, rheological features, and higher thermal conductivity. The researchers used a selection of different research methods, features, and models used to calculate the apparent thermo properties of nanofluids (i.e., thermal conductivity, viscosity, density, specific thermal energy) [2 - 9]. Various researchers also summarized the properties of nanofluids in the distribution and transfer of heat in a normal and compulsory manner to convection across different systems [10 - 13]. Improved thermal performance of nanofluids that can provide the first modernization of heat transfer, which is particularly important in the industrial and transportation sector, power generation, small-scale production, heat treatment for cancer, chemical and metal sectors. , as well as heating, cooling, ventilation and airconditioning. Nanofluids are also important in the production of nanostructured materials for the production of complex liquids and detergents from surface areas due to their special moisturizing and diffused properties [14]. An additional importance of nanofluid flow lies in the release of nano drugs as suggested by Kleinstreuer et al. [15]. In recent years, solar energy has had a dramatic impact. The apparent shortage of fossil fuels and environmental considerations will limit future use of fossil fuels. Therefore, researchers are encouraged to identify potential sources of energy. This has become increasingly fashionable as the cost of fossil fuels continues to rise. Many solar energy applications are economically viable and a small business system uses a few kilowatts of energy [16,17]. It is advisable to use solar energy for many varieties of applicati

\section{Nanoparticles and Nanofluids Properties}

A size of nanoparticles lies between 1 and 100 nanometers. Nanoparticles may or may not display features that are significantly different from those observed in microscopic particles or particles. Nanoclusters have at least one size between 1 and 10 nanometers and a smaller size distribution. Nanopowder are agglomerates of fine particles, nanoparticles, or Nanoclusters. Single-size nanometer crystals, or ultra-fine particles of a single domain, are commonly referred to as nanocrystals. Nanoparticles are of great scientific interest as they 
successfully form a bridge between masses and atomic or molecular structures. Bulk material should consist of a durable material no matter how large, but to a degree depending on the size of the nano-scale is often observed. Therefore, the properties of material change as their size approaches the nanoscale and as the percentage of atoms on the surface of the object becomes larger. The formation of nanoparticles is possible as the interaction of the particle and solvent is strong enough to overcome the difference in density, which often results in an object sinking or floating in a liquid. Nanoparticles also tend to have unpredictable optical properties as they are small enough to shut down their electrons and produce quantum effects. For example, gold nanoparticles appear deep red to dark solution. Nanoparticles have a very high surface area and volume, which provides high dispersing power, especially at high temperatures. Sintering can occur at low temperatures, on a shorter scale than larger particles. The fluid containing solid nanosized particles suspended in them is called "nanofluids." Suspended or nonmetallic metal nanoparticles alter transport characteristics and thermal transfer properties of the basic liquid. Improving heat transfer in solar panels is one of the key problems in energy conservation and integrated projects. Solar energy is widely used in such things as electricity generation, chemical processing, and thermal energy because of its renewable and non-polluting nature. Most solar water heating systems have two main components: a solar collector and a storage tank. The most common collector is called a flatplate collector but this has a low efficiency problem. Many ways have been introduced to increase the efficiency of the solar water heater. But the novel's method is to introduce nanofluids into the solar collector instead of the usual heat transfer fluid (like water).

\section{Nanofluids in Solar Energy Applications}

Initially, the use of nanofluids in collectors and water heaters is investigated for efficiency, economy, and environmental factors. Other studies conducted on thermal behavior and optical properties of nanofluids are also briefly reviewed, as these parameters can determine the nanofluid potential to improve the performance of solar energy.

\subsection{Solar heat Collectors}

Nanofluid puts the following advantages compared to conventional liquids that make them suitable for use in solar collectors: Solar energy absorption will be increased by changing the size, shape, material and volume of the nanoparticles. Stabilized nanoparticles increase surface area and liquid heat capacity due to the very small particle size. Stabilized nanoparticles improve thermal conductivity leading to improved efficiency of heat transfer systems. Liquid structures can be altered by a combination of different nanoparticles. The very small size of the nanoparticles allows them to pass through the pumps. The basic difference between conventional and nanofluids-based compounds is in the process of heating the active fluid. In the former case the sunlight is attracted to the surface, whereas later the sunlight is drawn directly into the active fluid (by radiation). When it reaches the recipient, the sun's rays transmit energy to nanofluids through diffusion and absorption.

These machines absorb incoming sunlight, convert heat, and transfer heat to liquids (usually air, water, or oil) that flow through the collection. The collected energy is extracted from the working liquid, either directly into hot water or a space cooler or thermal storage tank, where 
it can be extracted for use at night or on cloudy days [33]. Solar water heaters are the most popular devices in the field of solar energy. A solar collector is used to collect solar energy and transmits solar energy collected from passing water when it comes in contact with it, so it is always a matter of research to know how solar collectors convert solar energy into thermal energy. Solar collectors are classified as: Low or flat solar collectors and Solar collectors. Flat plates are very easy to build and are widely used as household appliances such as water heaters, air heaters, and solar panels; solar panels collectors are widely used in generating electricity, heating water with a high amount of bulk flow. Focus Solar collectors work much better than flat plate collectors, on the other hand they need a tracking system and require higher installation costs compared to flat plate collectors. The efficiency of the solar collector depends on the material of the liquid flowing into it. It has been found that the most common liquid used in solar collectors suffers from bad thermal conditions. A new phase of active water called "Nanofluid" can be used instead of conventional liquids, which have improved thermal properties and thus increase the thermal performance of the solar collector. Nonomaterial has unique mechanical, optical, electrical, magnetic and thermal properties where the average size of nanoparticles is less than $100 \mathrm{~nm}$. A very small amount of nanoparticles when dissolved in any soluble liquid (e.g., water, oil, ethylene glycol) can dramatically improve the thermal properties of liquids. The most commonly used materials that make nanofluids are: oxide ceramics (Al2O3, $\mathrm{CuO}$ ), nitride ceramics (AlN, SiN), carbide ceramics $(\mathrm{SiC}, \mathrm{TiC})$, metals $(\mathrm{Cu}, \mathrm{Ag}, \mathrm{Au})$, semiconductors (TiO2, $\mathrm{SiC})$, carbon nanotubes, composite materials (A170Cu30). Nanoparticles can be produced mainly by two processes; those Physical Processes and Chemical Procedures. Physical Processes include Inert Gas Condensation (IGC) and mechanical milling while Chemical Processes include Chemical Vapor Deposition (CVD), chemical precipitation and micro emulsion. To make Nanofluids, nanoparticles are suspended in a standard two-way heat transfer fluid called a single-step and two-step method. As described in paragraph.3 above in a one-step process the disintegration of the nanoparticle occurs simultaneously when in a two-step process the first nanoparticles are formed and the nanoparticles are dispersed in the basic water.

\subsection{Solar stills}

Much research has been done on solar stills and various methods have been developed to improve their efficiency. In more recent times, Gnanadason et al. [34] argued that the efficiency of sun exposure could be increased by using nanofluids. Their results showed that efficiency improved by $50 \%$ with the addition of nanofluids. However, it was not clear if the exact amount of nanofluid deposited in solar water was still. As the cost of nanofluid is very high, so economic potential must be considered. It has also been suggested that solar efficiency could be improved by adding dyes to liquids [35] have reported that solar efficiency increases by $29 \%$ by adding violet dye to water, which is significant. Clearly, nanofluids are more expensive than dyes. Therefore, it is a challenge to use nanofluids in solar stills. It can be used to reduce greenhouse gas emissions from the production of clean water. 


\subsection{Solar cells}

The efficiency of the solar cell can be improved by cooling the solar cells (shown in Fig.4). Elmir et al. [36] equated with numerical cooling of a solar cell by forced roaming in the presence of nanofluid. A12O3 and aqueous nanofluid were used for analysis. The thermal conductivity and viscosity of the nanofluid are calculated using Brinkman and Wasp models respectively. It has been concluded that the value of Nusselt is increased through the use of nanofluids which leads to improved cooling rate. But in a complete analysis the thermal conductivity and viscosity of the nanofluid were not considered.

\subsection{Solar Panels}

Nanofluids are a simple product of the growing world of nanotechnology. The formation of nanoparticles (size 1 to $100 \mathrm{~nm}$ ) dispersed in liquids such as water, oil, glycols and even air and other gases can rightly be called nanofluids. The first decade of nanofluid research focused mainly on measuring and modeling the thermo-base properties of nanofluids (thermal conductivity, density, viscosity, heat transfer coefficient). Because of its renewable and non-renewable nature, solar energy is often used in projects such as generating electricity, heating, and chemical processing. Solar power plants with higher receivers have lower energy conversion rates due to greater loss of assist at higher temperatures. Nanofluids have recently found compatibility in systems that require rapid and efficient heat transfer such as industrial applications, cooling microchips, very small liquid applications, etc. The average performance of recently used solar panels was found to be $44.7 \%$ with the use of nanofluids. can be increased by $10-15 \%$, and with Plasmonic Nanofluids by $20 \%$.

\subsection{Solar energy storage}

A typical solar energy storage system requires storage space for high temperature fluctuations and thermal energy. However, very few materials are available with such properties and can be used at high temperatures. In more recent times, Shin and Banerjee [37] argue that abnormal improvements in certain temperature levels may occur in nanofluids that are higher than normal. It was found that the thermal conductivity of nanofluid increased by $14.5 \%$ when Alkaline metal chloride eutectic salt was added to silica nanoparticles at $1 \%$ mass concentration. This may therefore be suitable for use in a solar energy storage system. Paraffin is suitable because of its beneficial properties, as it has high hidden thermal strength and low cooling and low cost. Phase Change Material can be used to store solar energy. Wawa et al. [38] numerically mimics the thermal energy of $\mathrm{Cu} /$ paraffin nanofluids PCMs. The results show that with 1 wt. $\% \mathrm{Cu} /$ paraffin, the melting time can save $13.1 \%$. Therefore, it has been concluded that the use of nanoparticles is an effective way to improve the heat transfer rate in the latent energy storage system as shown in Fig.5.

\subsection{Thermal systems}

A photovoltaic / thermal system (PV / T) is a composite structure that converts part of the sun's rays into electricity and half to heat [39]. One can investigate by examining the effects of using different nanofluids at a cooling rate, and, consequently, the efficiency of PV / T systems. The effects of different volume components, nanoparticle size on system efficiency can be studied. A review of the literature shows that more research has been done on the 
ability of nanofluids to cool different heating systems such as electric devices [40 - 42], motor radiator [43], and sub-station heat sinks [44]. Therefore, using nanofluids to cool the PV / T system may make sense

\subsection{Thermal Properties of Nanofluids}

The thermal properties of nanofluids depend largely on the size and volume of the nanoparticles in the basic liquid. The heat transfer characteristics of nanofluids also depend on the sonication time of the nanoparticles and the quality of sonication used. Therefore, as mentioned the high value of thermal conductivity and physical properties of thermo e.g. density, viscosity etc. improves heat absorption capacity, a certain amount of heat and heat transfer properties of nanofluids. It can be noted that the same as the efficiency of the collector of the temperature difference of the nanofluid rises by half the lower volume. The higher the volume, the greater the height, the viscosity and the volume. It is known that the thermal conductivity of solids is greater than that of liquids. The liquid commonly used for heat transfer such as water and ethylene has a lower efficiency compared to the thermal conductivity of solids, especially metals. Thus the addition of solid particles to a liquid can increase fluid consistency. When nanofluids are used as the active water for direct solar absorbers, thermal properties of nanofluids are essential for solar use. The thermal properties of the image are very important in assessing solar absorption of nanofluids because they directly reflect the solar absorption capacity of nanofluids. Viscosity and rheological behavior are not only important parameters for nanofluid stability and flow behavior but also affect the heat transfer efficiency of direct solar absorberers. Thermal conductivity is an important parameter of heat transfer fluid. It also affects the efficiency of heat transfer collectors. Significant efforts have been made on the rheological and thermal conductivities of nanofluids, and these studies are useful in researching nanofluids as an effective solar absorption liquid.

\subsection{Electronic Appliances}

Due to the high density of the chips, the design of the highly integrated electronic components makes heat dissipation very difficult. Advanced electronic devices face the challenges of temperature control from a high degree of heat production and the reduction of available space for heat dissipation. Therefore, a reliable thermal control system is essential for the efficient operation of advanced electronic components. In general, there are two ways to improve the heat emission of electrical equipment. One is to find the correct geometry of cooling equipment; the other is to increase the heat transfer capacity. Nanofluids with high thermal conductivities are predicted by variable heat transfer coefficients compared to those in basic liquids. Recent studies have shown that nanofluids can increase the heat transfer coefficient by increasing the thermal conductivity of the cooler. Jang and Choi have developed a cool new cooling sink, a small heat sink containing nanofluids. [46] Higher cooling performance was achieved compared to a device that uses clean water as a working environment. Nanofluids reduce both temperature resistance and temperature difference between the wall of a small hot and cold channel. The integrated heat sink of a small nanofluid channel has become as powerful as the next generation cooling devices to remove very high temperatures. Nguyen et al. design a closed fluid cycle to investigate the 
development of heat transfer fluid by changing the basic fluid (liquid water) with nanofluid composed of liquid water and $\mathrm{Al} 2 \mathrm{O} 3$ nanoparticles in various locations [47]. The thermal activity of Silicon microchannel using nanofluids containing $\mathrm{Cu}$ nanoparticles was analyzed [48]. It has been found that nanofluids can improve performance compared to the use of clean water as a coolant. The development was due to increased thermal cooling performance and the effect of nanoparticle thermal dispersion. Another advantage was that there was no decrease in additional pressure, as the nanoparticle was smaller, and the fractional particle volume was lower.

\subsection{Storage Power}

Temporary variations in energy source and energy requirements necessitated the development of a storage system. Thermal energy storage in the form of sound and subtle heat has become an important part of energy management with an emphasis on efficient use and conservation of heat and solar energy in industry and facilities [49]. Concealed heat retention is one of the most effective ways to conserve heat. Wu et al. tested the potential of $\mathrm{Al} 2 \mathrm{O} 3-\mathrm{H} 2 \mathrm{O}$ nanofluids as a new phase converter (PCM) in the thermal energy storage of cooling systems. Heat response experiments showed the addition of $\mathrm{A} 12 \mathrm{O} 3$ nanoparticles significantly reduced water cooling rate, improved early egg formation, and reduced overall egg proliferation. By adding only $0.2 \mathrm{wt} \% \mathrm{Al} 2 \mathrm{O} 3$ nanoparticles, the total freezing time of $\mathrm{Al} 2 \mathrm{O} 3-\mathrm{H} 2 \mathrm{O}$ nanofluids can be reduced by $20.5 \%$. Liu et al has developed a new type of nanofluid modifier (PCMs) by introducing a small number of $\mathrm{TiO} 2$ nanoparticles into a complete $\mathrm{BaCl} 2$ aqueous solution [50]. PCM nanofluids had significantly higher thermal conductivity compared to the base material. Cold storage capacity / supply level is significantly higher than that of $\mathrm{BaCl} 2$ aqueous solution without the addition of nanoparticles. The high thermal performance of PCM nanofluids indicates that they have the ability to replace common PCMs in cold storage systems. Copper nanoparticles are effective additives for improving the temperature and cooling of PCMs [51]. In compounds containing 1wt\% copper nanoparticle, the heating and cooling times can be reduced by 30.3 and $28.2 \%$, respectively. Hidden temperatures and temperatures change slightly after 100 heat cycles.

\subsection{Solar absorption}

Solar energy is one of the best sources of renewable energy that has little effect on the environment. A standard solar collector collector is a well-established technology, and has been proposed for a variety of applications such as water heating; however, the efficiency of these collectors is limited to the absorption properties of the active fluid, which is worse than the standard fluids used by solar collectors. Recently, these technologies have been integrated with the emerging technology of nanofluids and the liquid-nanoparticle configuration to form a new class of nanofluid-based solar collectors. Otanicar et al. reported experimental results to solar collectors based on nanofluids made from a variety of nanoparticles (CNTs, graphite, and silver) [52]. Performance improvements were up to 5\% for solar thermal collectors using nanofluids as absorption media. Additionally, the experimental data included a numerical model of the solar collector containing direct absorption nanofluids. Test and numerical results showed a rapid initial increase in efficiency with half the volume, followed by a reduction in the level of efficiency as half the volume continued to increase. Theoretical 
studies on the possibility of using an indirect solar collector have shown that the presence of nanoparticles increases the absorption of incident radiation more than nine times over pure water [53]. Under the same operating conditions, the efficiency of the absorbent solar collector using nanofluid as the active fluid was found to be $10 \%$ higher (on a complete basis) than that of a flat plate collector. Otanicar and Golden examined all the economic and environmental impacts of technology in comparison with conventional solar collectors using the life cycle test method [54]. Sani et al investigated the optical and thermal properties of nanofluids that include the liquid suspension of single-wall carbon nanohorns [55]. The contrast observed by the nanoparticle-indused spacecraft has been shown to be promising, resulting in significantly higher solar absorption. Both of these effects, along with the possible chemical activity of carbon nanohorns, make this new type of nanofluid more attractive in increasing the efficiency of a device that absorbs sunlight.

\section{Conclusion}

Solar energy is one of the purest forms of renewable energy resources. A standard solar collector is a well-designed technology with a variety of applications such as water heating, space heating and cooling. However, the thermal efficiency of these collectors is limited by the absorption characteristics of the active fluid, which is not very good for a typical flat plate collector. Recently, the use of nanofluids, which is a liquid-nanoparticle colloidal dispersion as an active liquid has been found to improve the thermal efficiency of a solar flat plate collector by 30 to 35 percent. Nanofluids are an advanced liquid that contains nano-sized particles that have emerged over the past two decades. Nanofluids are used to improve system performance in many solar systems. This paper provides an overview of recent developments in nanofluid research, including preparation methods. From an economic and environmental point of view, reviews have shown that the use of nanofluids by collectors leads to reduced $\mathrm{CO} 2$ emissions and annual electricity and fuel savings. Many researchers have reported, working on the use of nanofluids in solar cells, solar energy storage, and solar suspension are also being reviewed. It will therefore be a promising effort to develop research projects on the use of nanofluids in various solar systems such as solar absorption, solar thermoelectric cells, and thermal conductivity of nanofluids, electronic applications, energy conservation and solar absorption.

\section{References:}

1. C. H. Lo, T. T. Tsung, L. C. Chen, C. H. Su, and H. M. Lin, Journal of Nanoparticle Research. 7(2005) 313-320

2. H. T. Zhu, Y. S. Lin, and Y. S. Yin, Journal of Colloid and Interface Science. 277(2004) $100-103$

3. H. B"onnemann, S. S. Botha, B. Bladergroen, and V. M. Linkov, Applied Organometallic Chemistry. 19 (2005) 768-773

4. A. K. Singh and V. S. Raykar// Colloid and Polymer Science. 286(2008)1667-1673,

5. A. Kumar, H. Joshi, R. Pasricha, A. B. Mandale, and M. Sastry, Journal of Colloid and Interface Science. 264 (2003) 396-401

6. W. Yu, H. Xie, X. Wang, and X. Wang, Nanoscale Research Letters. 6 (2011) 47, 
7. H. T. Zhu, C. Y. Zhang, Y. M. Tang, and J. X. Wang, Journal of Physical Chemistry C, 111 (2007)1646- 1650.

8. Y. Chen and X. Wang, Materials Letters.62 (2008) 2215- 2218.

9. X. Feng, H. Ma, S. Huang, Journal of Physical Chemistry B. 110 (2006) 12311-12317

10. W. Yu, H. Xie, L. Chen, and Y. Li, Colloids and Surfaces A. 355 (2010) 109-113

11. L. Wang and J. Fan, Nanoscale Research Letters. 5 (2010) 1241-1252

12. S.A. Kalogeria, Solar Energy Engineering: Processes and Systems, Elsevier, Oxford, (2009)

13. M.K. Gnanadason, P.S. Kumar, S. Rajakumar, M.H.S. Yousuf, I.J.AERS. 1(2011) 171-177

14. S. Nijmeh, S. Odeh, B. Akash, Int. Commun. Heat Mass Transfer. 32 (2005)565-572

15. M. Elmir, R. Mehdaoui, A. Mojtabi, Energy Procedia. 18 (2012)594-603

16. D. Shin, D. Banerjee, Int. J. Heat Mass Transfer. 54 (2010)1064-1070

17. S. Wua, H. Wanga, S. Xiaoa, D. Zhub, Energy Procedia. 31(2012)240-244

18. Omid Mahian, Ali Kianifar, Soteris Kalogirou, Ioan Pop, Somchai Wongwises, Heat Mass Transfer. 57 (2012)582-594

19. A. Bouzoukas, Ph.D Thesis, University of Nottingham (2008)

20. C.T. Nguyen, G. Roy, C. Gauthier, N. Galanis, Appl. Therm.Eng. 27 (2007) 1501-1506.

21. M. Elmir, R. Mehdaoui, A. Mojtabi// Energy Procedia. 18 (2012) 724-732.

22. A. Ijam, R. Saidur, Appl. Therm. Eng. 32 (2012) 76-82.

23. S.M. Peyghambarzadeh, S.H. Hashemabadi, M. Seifi Jamnani, S.M. Hoseini,Appl. Therm. Eng. 31 (2011) 1833-1838.

24. T. Hung, W. Yan, Int. J. Heat Mass Transfer. 55 (2012)3225-3238.

25. H. Fan, R. Singh, A. Akbarzadeh, J. Electron. Mater. 40 (2011)1

26. S. P. Jang and S. U. S. Choi, Applied Thermal Engineering. 26 (2006)2457-2463

27. C. T. Nguyen, G. Roy, N. Galanis, and S. Suiro, In Proceedings of the $4^{\text {th }}$ WSEAS International Conference on Heat Transfer, Thermal Engineering and Environment, Elounda, Greece (2006) 103-108

28. H. Shokouhmand, M. Ghazvini, and J. Shabanian, In Proceedings of the World Congress on Engineering (WCE '08), London, UK, 3 (2008)

29. M. F. Demirbas, Energy Sources Part B. 1 (2006)85-95, 2006.

30. S. Wu, D. Zhu, X. Zhang, and J. Huang, Energy and Fuels. 24 (2010)1894-1898

31. Y. D. Liu, Y. G. Zhou, M. W. Tong, and X. S. Zhou, Microfluidics and Nanofluidics. 7(2009) 579-584

32. T. P. Otanicar, P. E. Phelan, R. S. Prasher, G. Rosengarten, and R. A. Taylor,Journal of Renewable and Sustainable Energy, 2 (2010) 13

33. H. Tyagi, P. Phelan, and R. Prasher, Journal of Solar Energy Engineering.131 (2009) 0410041-0410047 